\title{
Exploring links between culture and biodiversity: studying land use intensity from the plot to the landscape level
}

\author{
Matthias Bürgi ${ }^{1} \cdot \mathrm{Li} \mathrm{Li}^{2} \cdot$ Thanasis Kizos $^{3}$
}

Received: 6 January 2015/Revised: 15 June 2015/Accepted: 16 July 2015/

Published online: 29 July 2015

(C) Springer Science+Business Media Dordrecht 2015

\begin{abstract}
In recent years, the term biocultural diversity has been promoted to raise awareness for the interrelationship between culture and biodiversity. Whereas the term is hard to conceptualize in general, specific links between culture and biodiversity can be explored. In this paper, we focus on land use, which is on one hand culturally coined, and has on the other hand far-reaching impacts on biodiversity. The specific effects of land use on biodiversity depend on its intensity, which can be parameterized in different way, not the least depending on the scale of observation. Based on a short review of different approaches on how to assess land use intensity (LUI), we propose a new conceptual framework reflecting the scaled nature of the linkages between land management and biodiversity. From the plot to the landscape level, different aspects of LUI are becoming relevant, some of which we illustrate with case studies from China, Greece and Switzerland. We conclude on how the framework proposed can further our understanding on the interconnectedness of humans and their environment.
\end{abstract}

Keywords Land use change - Land use intensity (LUI) - Landscape dynamics . Biodiversity · Disturbance

Communicated by Mauro Agnoletti.

Matthias Bürgi

matthias.buergi@wsl.ch

$\mathrm{Li} \mathrm{Li}$

li.li@wildlife.uni-freiburg.de

Thanasis Kizos

akizos@aegean.gr

1 Research Unit Landscape Dynamics, Swiss Federal Research Institute WSL, 8903 Birmensdorf, Switzerland

2 Chair of Wildlife Ecology and Management, Albert-Ludwigs-Universität Freiburg, 79106 Freiburg, Germany

3 Department of Geography, University of the Aegean, University Hill, Mytilene 81100, Greece 


\section{Introduction}

The diversity of life on earth encompasses the natural and cultural dimensions and the interrelationship between the two, including aspects such as the impact of humans on species occurrence on scales from the square meter to the globe, or in reverse the role of species in local traditions, food and folklore. To raise awareness for the importance of this interrelationship, the term biocultural diversity has been promoted (e.g. Loh and Harmon 2005). This term is on one hand compelling, as it is obvious that culture has been shaped by the natural context, and in turn has left traces in this natural context. However, it is hard to conceptualize and to envision how much this approach may contribute to a deeper understanding of and for the diversity of life on earth.

One of the challenges is rooted in the fact that natural diversity is the central research topic of ecology with a long tradition in measuring, describing and classifying the elements of natural diversity - most prominently species - aiming at understand their occurrence and distribution (Magurran 2004). Cultural diversity as a whole, on the other hand, eludes itself from similar approaches, which however can be performed for selected aspects, such as languages (Abramov and Mehler 2011), belief systems (Sutton and Anderson 2004), or food (Carolan 2012). Consequently, studies of the interrelationship between the two dimensions are focused on aspects, for which also the cultural dimension can be categorized, such as establishing links between language diversity and biodiversity (Sutherland 2003; Maffi 2005). Alternatively, studies focus on selected specific outcomes of the interrelationship, such as agrobiodiversity (Lomba et al. 2014), including home gardens (Galluzzi et al. 2010), or ecosystem development shaped by natural and anthropogenic aspects alike (Targetti et al. 2014).

Land use is one of the most obvious ways in which humans are shaping the earth, encompassing resource extraction, agriculture, forestry, building activities etc. These activities have had tremendous impacts on species occurrence, but they are at the same time also culturally coined, by traditions, law, technology etc. (Bürgi et al. 2004). Land use systems evolve over time, influenced by feedback mechanisms from "natural" effects, such as erosion which requires adapted strategies to manage land without such unwanted side effects. Even subtle changes in how the land is managed can have effects on productivity and species occurrence, as thresholds for habitat quality might be surpassed, eradicating certain species, and promoting others (Russell 1993). Therefore, the specific practices have to be known to allow linkages to the related biodiversity. In ecological terms, land management can be seen as an anthropogenic disturbance to the ecosystem (e.g. Gimmi et al. 2008). Parameterizing land use as disturbance is an important step in recognizing the entity and diversity of human impacts on the ecosystems and the related biodiversity. Disturbances can be characterized by a specific disturbance regime, expressed by spatial extent, intensity, and frequency (Folke et al. 2010). Whereas the spatial extent and frequency are rather simple to assess, intensity is harder to classify, given the diversity of aspects to consider.

In this paper, we attempt to explore links between culture and biodiversity by focusing on the intensity of land use. How intensively land is used, is not the least determined by cultural driving forces, i.e. changes in land use intensity (LUI) reflect the local culture and its development over time. At the same time, LUI has direct as well as indirect consequences on biodiversity from the plot to the landscape level. Thus, we consider LUI to be an important concept to explore links between cultural diversity and biodiversity at various scales. 
To achieve this, we (a) present different approaches on how land use intensity (LUI) has been conceptualized, (b) propose - with a focus on agricultural landscapes - a conceptual framework reflecting the scaled nature of the linkages between land management and biodiversity, (c) illustrate the concept with case studies from China, Greece and Switzerland and (d) conclude with some thoughts on how the approach can further our understanding on the interconnectedness of humans and their environment.

\section{Conceptualizing land use intensity (LUI)}

Already in the 1960s, questions related to the intensity of agricultural production and its change were studied, especially in social sciences (Erb et al. 2014). The importance of considering changes in LUI and the related effect on ecosystem services (ES) has again been discussed increasingly in the last years, despite its actual recognition in studies is not where it should be (Erb et al. 2014). Various concepts on how LUI can be conceptualized-a prerequisite for its integration in empirical approaches-have been developed, but major obstacles remain:

(a) data needed to assess the degree of human activity might not be available at the scale and resolution needed,

(b) LUI has an effect on various ES at different scales, but every scale has its own requirements regarding conceptualization,

(c) LUI encompasses various aspects and dimensions. Combining them into one index, might blur aspect being relevant for assessing effects on biodiversity, e.g. due to very specific species traits.

Input-output analyses are appropriate for studies looking at e.g. changes in energy efficiency of farming at a national or even global scale, but they are not able to explain changes in biodiversity on the plot or farm-level, where a multitude of additional factors come into play, such as habitat diversity on the landscape level or machinery used on a specific plot of land.

These differences are well illustrated by a short review of some of the recent additions to the growing body of literature on LUI. For analyses on large and even global scale, Kuemmerle et al. (2013) and Erb et al. (2013) discuss a series of metrics assessing LUI, focusing on input metrics (e.g. fertilizer, cropping frequency, rotation lengths), output metrics (e.g. yields, capital productivity, residue/felling ratios in forestry) and metrics which put either input or output metrics into relations to system properties, such as the human appropriation of primary production (HANPP) (see Haberl et al. 2007).

For large scale approaches with a focus on specific ecosystem services, LUI is often reduced to a single indicator, such as by Deguines et al. (2014), who take agricultural yields as a proxy for level of intensification and study its correlation with crop pollination service.

To gain a more mechanistic understanding on how changes in LUI might affect biodiversity (e.g. Nagendra et al. 2013), scales on which the individual farmer and his activities on the land take place have to be considered. We can distinguish between sectorial approaches, farm-level approaches, and landscape approaches. Sectorial approaches focus on specific land cover types, such as Blüthgen et al. (2012), who propose and test an additive index of LUI in grasslands, integrating information on fertilization, mowing and grazing. Aspects missing in this index are time-lag effects of former intensive 
management, i.e. periods in the past with higher fertilization, which still have an effect on present soil chemistry, changes in water availability and saturation, such as irrigation and drainage, mowing technology used, and interactions among different, e.g. neighboring land use types. To overcome some of these limitations, Blüthgen et al. (2012) suggest to use an index integrating LUI across several years for studies on effects on slowly responding organisms and processes. The index developed by Blüthgen et al. (2012) has been applied by Börschig et al. (2013) to study the interrelationship between LUI and butterfly communities.

In a farm-level approach Gaudino et al. (2014) distinguish between conventional (most intensive), integrated (intermediate intensity), and organic (least intensive) farming and study the relationship between input and environmental pressure resulting from the different farming types.

On the landscape level, neighborhood effects come into play, as species often do not depend on one habitat alone, but on different habitats in different stages of their life. Plot size and characteristics, but also the landscape mosaic therefore also should be integrated (Diacon-Bolli et al. 2012; Zulka et al. 2014).

\section{A framework to link LUI and biodiversity}

For a mechanistic understanding on how LUI influences biodiversity, the spatial level on which species occur or are absent has to be considered, e.g. for plants the specific place with its specific growing conditions. At the same time, local species occurrence depends on pattern and processes at larger scale, such as habitat configuration on the landscape level (Farina 2006). This holds especially true for species, which require different habitat types during their life cycle. Consequently, the scale dependency of assessing LUI has its equivalent in the scale dependency of biodiversity, as different levels and qualities of diversity emerge as spatial (and temporal) scales change. A concept for linking LUI and biodiversity therefore has to be multi-scale, ranging from the plot to the landscape scale. We propose a conceptual graph (Fig. 1) locating land use and LUI in the cultural sphere (together with most of the relevant driving forces). The interrelationship between land use and the various dimensions of biodiversity takes place on various spatial levels.

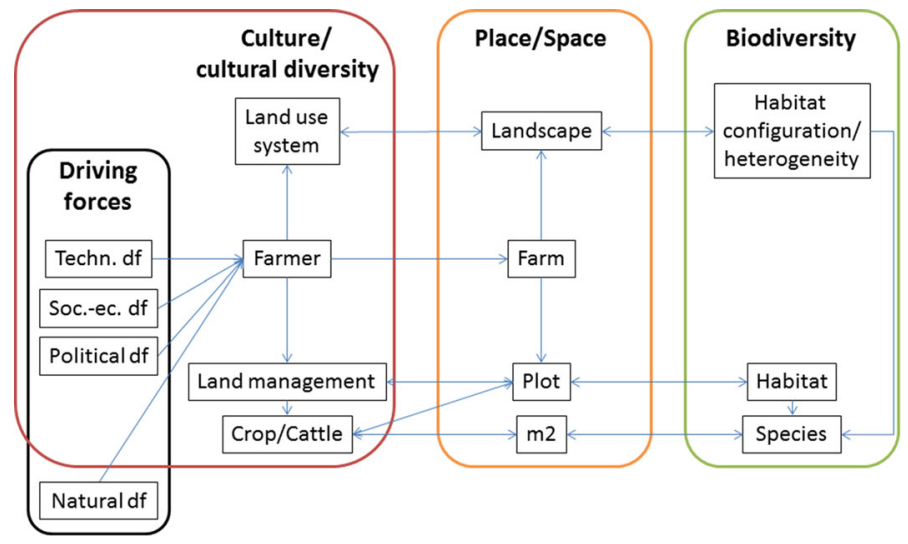

Fig. 1 Conceptual graph depicting the interrelationship between culture and biodiversity. A more detailed description of the graph can be found in the text 
The uppermost level of Fig. 1 depicts how land use systems shape landscapes, which in turn provide habitats in a characteristic configuration. The term and concept of landscape has been used in diverse disciplines and research practices (Antrop 2006), foremost in landscape ecology and land change science (Turner et al. 2007). The so-called "landscape scale" (Farina 2006), is composed of the physical-geographical features of an area, which create the fundamental forms and shapes, such as the relief, the geomorphology, the climate, and so forth; the biosphere, which is comprised by the living organisms and their spatial formations and interactions (Tsilimigkas and Kizos 2014); and man-made constructions, including fields, roads, buildings, urban formations, and other artefacts (Howard 2011). Another inherent characteristic of the landscape is its dynamic nature (Marcucci 2000). These changes are the result of interacting natural and cultural factors that act upon each other, often over different temporal scales (Antrop 2004). Therefore, we propose the landscape level as the appropriate spatial level for linking larger scale land use systems, their intensity and their effects on habitat configuration and larger scale heterogeneity.

At the same time, the plot level with a specific land management, which can be interpreted as anthropogenic disturbance, and the related biodiversity on the very local level has to be considered (Fig. 1), as plots are the single stones of the landscape mosaic, i.e. providing habitats for specific species. The landscape mosaic includes all different land management systems at their actual spatial complexity, with plots from one system interspersed with plots from other systems. In this mosaic, the different systems can be defined with criteria relevant to the particular landscape or area (e.g. land cover, type of crops, combinations of landscape features, etc.). Scaling down from the landscape level, the intensity of each system can then be assessed at the plot level and so can be the effects of LUI on biological diversity. This assessment is very important for a realistic depiction of the actual inputs and outputs, but mostly for the resulting effects on resources and diversity. Up-scaling again at the landscape level yields a series of averages from the plot level assessments for the system as a whole. The challenge lies in the interactions of these plot level effects at the landscape level and the spatial interactions of the actual mosaic. Depending on the study aims, even more detailed, smaller scale analyses of LUI might have to be undertaken, looking at specific land management features, crops, grazing animals etc., and their effect on specific species with their characteristic requirements and live history traits (Fig. 1).

In agricultural landscapes, the core agent on the land is the farmer, who organizes the management of the different plots of his farm to form an economically viable economic entity. Understanding the long-term development of biodiversity in agricultural landscape requires insights in the main factors shaping farm management and influencing the farmers decisions. We therefore propose to add to the conceptual graph (Fig. 1) an intermediate level, on which the farmer as actor and the farm as his sphere of action are positioned between the landscape and the plot level. The well-established concept of driving forces of landscape change (e.g. Bürgi et al. 2004) allows to assess systematically the context, in which the farmer operates, including technological, socio-economic and political driving forces, which are all culturally shaped. Additional natural driving forces, such as topographic features or accessibility, form specific constraints which the farmer has to take into account and have an influence on his decisions.

In the following chapter, we illustrate different aspects of the framework proposed at examples from three case study areas (Fig. 2): the Eastern Tibetan Plateau in China, Lesvos Island in Greece and the alpine landscape of Switzerland. The conceptualization of the link between culture and biodiversity with the use of LUI is based on the definitions of biodiversity and the methodologies used to measure it, but also the scale used. The case 


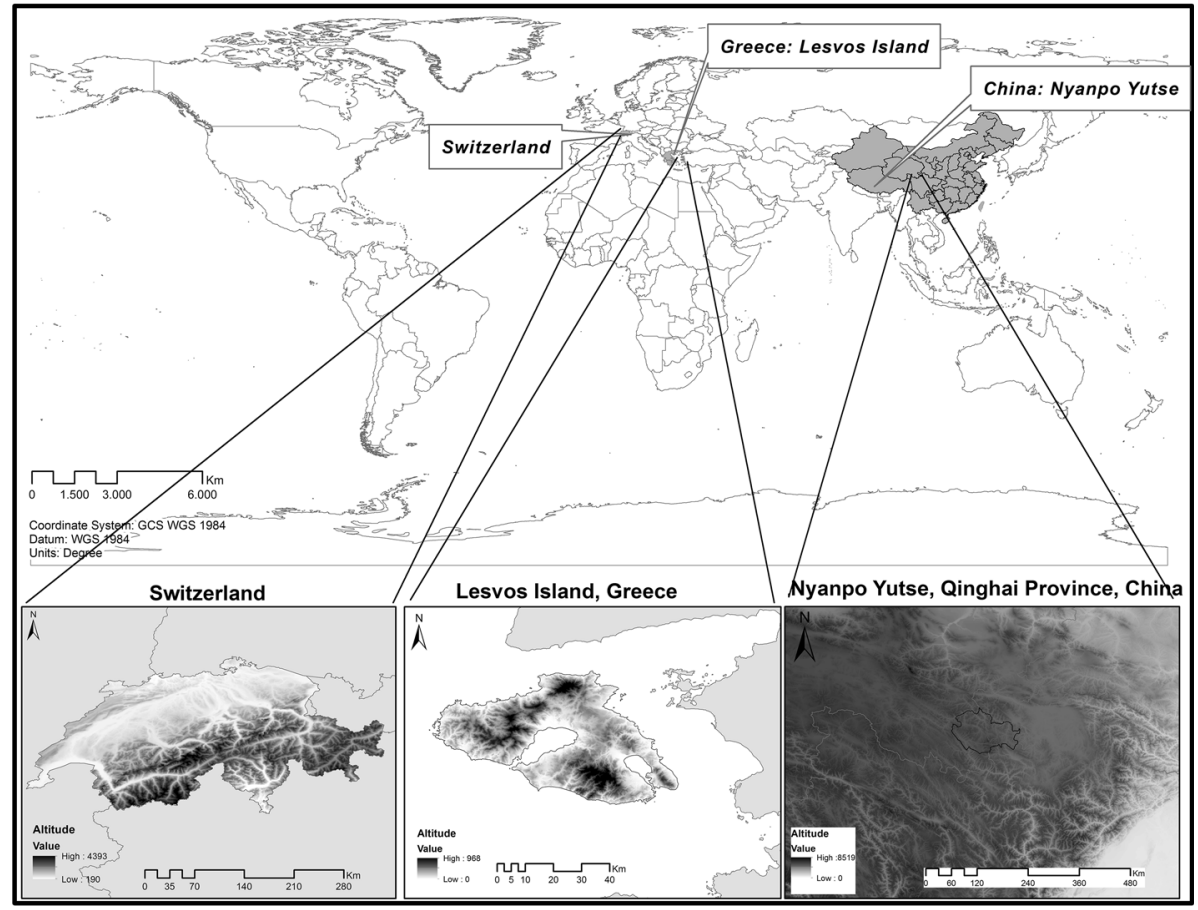

Fig. 2 Map showing the location of the three case study regions

studies selected reflect this diversity, by representing different cultures, different sources used, different methodologies of estimating the link between LUI and biodiversity, while they also focus on different scales.

\section{Assessing the intensity of land use systems in the Eastern Tibetan Plateau of China}

Nyanpo Yutse region lies to the eastern edge of the Qinghai-Tibetan Plateau. The alpine landscape covers $8760 \mathrm{~km}^{2}$ with altitudes ranging from 3600 to $5700 \mathrm{~m}$. The dominant land use form is pastoralism since crop cultivation is impossible in the low precipitation and temperature environment. Usable pastures accounted for $76 \%$ of the total administrative territory of the study area in Jiuzhi County (Jiuzhi County Government Office 2012). Yak, sheep and horses are the keystone domestic animals and are known as the "nomads' golden triangle". The highland pastures provide unique habitats for a rich diversity of alpine flora and fauna. Some are endangered or endemic to the region such as the Snow Leopard (Panthera uncia) and Tibetan bunting (Emberiza koslowi). Livestock grazing and trampling is the major biological disturbance to the agricultural landscape and regulates the distribution of local biodiversity. Recent pollen core study of the eastern Qinghai-Tibetan Plateau found that the vast short-grass landscape is significantly formed by historical grassland management activities (Miehe et al. 2009). 
However, during the past decades the traditional pastoral land use system has undergone significant changes which are driven by a series of sequential grassland policies. In Nyanpo Yutse the stocking rate increased steadily under the People's Commune regime which was installed in 1959. The number peaked in 1978 (Fig. 3) after a nationwide zeal for high productivity. The early 1980s started the phase of collective economy dismantling. Livestock of the production brigades were distributed equally per capita in 1984, which was followed by the leasing of winter pastures to nomadic households in 1994 and the leasing of summer pastures in 1997 (Golok Overview Editors' Group 2009). During this privatization period pasture management unit switched from the brigades to individual households and land use decision-makings were carried out at the family level. From the 1980s to 1990s the yak number remained at a high level whilst the sheep number dropped sharply (Fig. 3). Production brigades' winter and summer pastures were distributed to each household based on their family sizes of the year 1984. Boundary adjustments or leasehold transfers were infeasible and lawless despite of the population growth after 1984. Nomads were highly motivated to establish wire fences to designate private pastures. From 1984 to 1995 there were 93,000 ha fenced pastures in Nyanpo Yutse and a "fence fever" was rushed in the early 1990s (Jiuzhi County Annals Editor's Group 2005). Like other inner Asia regions, this privatization process resulted in the pastoral mobility loss and the declining of nomadism (Humphrey and Sneath 1999). Nowadays nomads in Nynapo Yutse are practicing the de facto transhumance way of livestock grazing: moving basically twice a year between fixed winter-spring pastures and fixed summer-autumn pastures. In 1996 the state launched the "grassland four-way program" providing subsidies to winter permanent settlements and livestock shelters construction which additionally prolonged and intensified the use of winter pastures. Being aware of accelerated grassland degradation in western China the central government's has implemented the grazing prohibition and

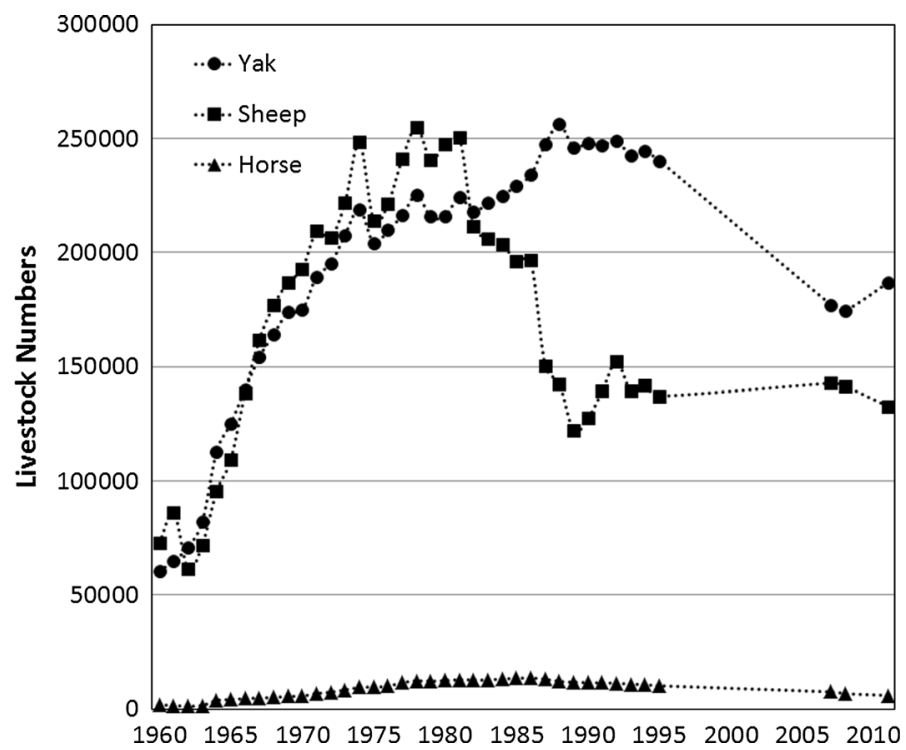

Fig. 3 Livestock numbers and compositions in Nyanpo Yutse from 1960 to 2011 (Jiuzhi County Annals Editor's Group 2005; Jiuzhi County Government Office 2012) 
grassland conservation policy since 2003 (in Chinese pinyin: tui ти huan cao) aiming at reducing livestock numbers and restoring degraded pastures. During the past decade, stocking rate has been restricted in Nyanpo Yutse (Fig. 3). However, the alpine meadow landscape is still suffering from the legacy effect of intensified land use from the 1970s to the 1990s.

The contemporary transformation of the traditional pasture land use system has led to observable changes in landscape configuration and biodiversity distribution. Official data reported $39 \%$ of the grassland are degraded to the medium or high level in the study area, among which $6.7 \%$ has completely lost its vegetation cover and is called "black beach" (Jiuzhi County Government Office 2012). However, very few studies have been carried out to understand the process and pattern of the degradation (Harris 2010). Research in the adjacent area shows that heavy grazing can significantly modify vegetation structure and the composition of plant communities (Zhou et al. 2006). Long-term heavy grazing tend to create a homogeneous and resource-deficient landscape (Fig. 4a) which is inhabited only by a few highly adaptive organisms, e.g. Plateau Pika (Ochotona curzoniae), Whiterumped and Rufous-necked Snowfinches (Montifringilla taczanowskii and M. ruficollis) (Arthur et al. 2008). On the contrary, livestock grazing of mixed intensity levels is able to create a high patchiness in an originally uniformed landscape. In Fig. 4b fenced winter pastures bearing a spectrum of spatial grazing intensities form a checkerboard-like habitat matrix. On one hand fencing is considered threatening for wild ungulates since it can exacerbate habitat fragmentation (Zhang et al. 2014). On the other hand the landscape mosaic can also provide small mobile organisms such as passerine birds with diverse food resources and nesting structures and enhance alpha biodiversity. The purpose of our ongoing study in Nyanpo Yutse is to understand the interrelationships of land use changes, their driving forces and resulting biodiversity consequences. The ideal research approach would be firstly to count and map the past and present pastoral land uses, and next to examine the responding habitat dynamics and avian biodiversity distributions for different land-use change regimes. However, the major challenge of linking up these two steps is to conceptualize and parameterize LUI in a way that it can be compared across space and time in the study region. Therefore, we develop the following definition of LUI.

The Nyanpo Yutse pasture systems have three major components: compositional grazing intensity, temporal grazing intensity and spatial grazing intensity. The disturbance regimes of livestock grazing regulate biodiversity distribution at the landscape scale. To examine the impact of land use changes to the alpha and beta diversity distribution we propose using a LUI index which is a dependent variable integrating the three independent parameters (Table 1): (1) Compositional grazing intensity (C) which unifies the disturbances caused by the three types of domestic animals. The widely accepted livestock measure for the Qinghai-Tibetan Plateau is "sheep unit". In the study area one yak equals to four sheep units and one horse to six sheep units (Golok Overview Editors' Group 2009). (2) Temporal grazing intensity (T) which is measured by usage days of a year. In Nyanpo Yutse winter pastures are normally used for 202-242 days a year, and summer pasture 123-163 days (Jiuzhi County Annals Editor's Group 2005). We standardize the variable through dividing it by 365 days. (3) Spatial grazing intensity (S) which suggests the pasture size in hectare and is reciprocal proportional to the LUI. Thus we define the LUI as:

$$
\text { LUI }=\frac{\mathrm{C}}{\mathrm{S}} \times \frac{\mathrm{T}}{365}
$$



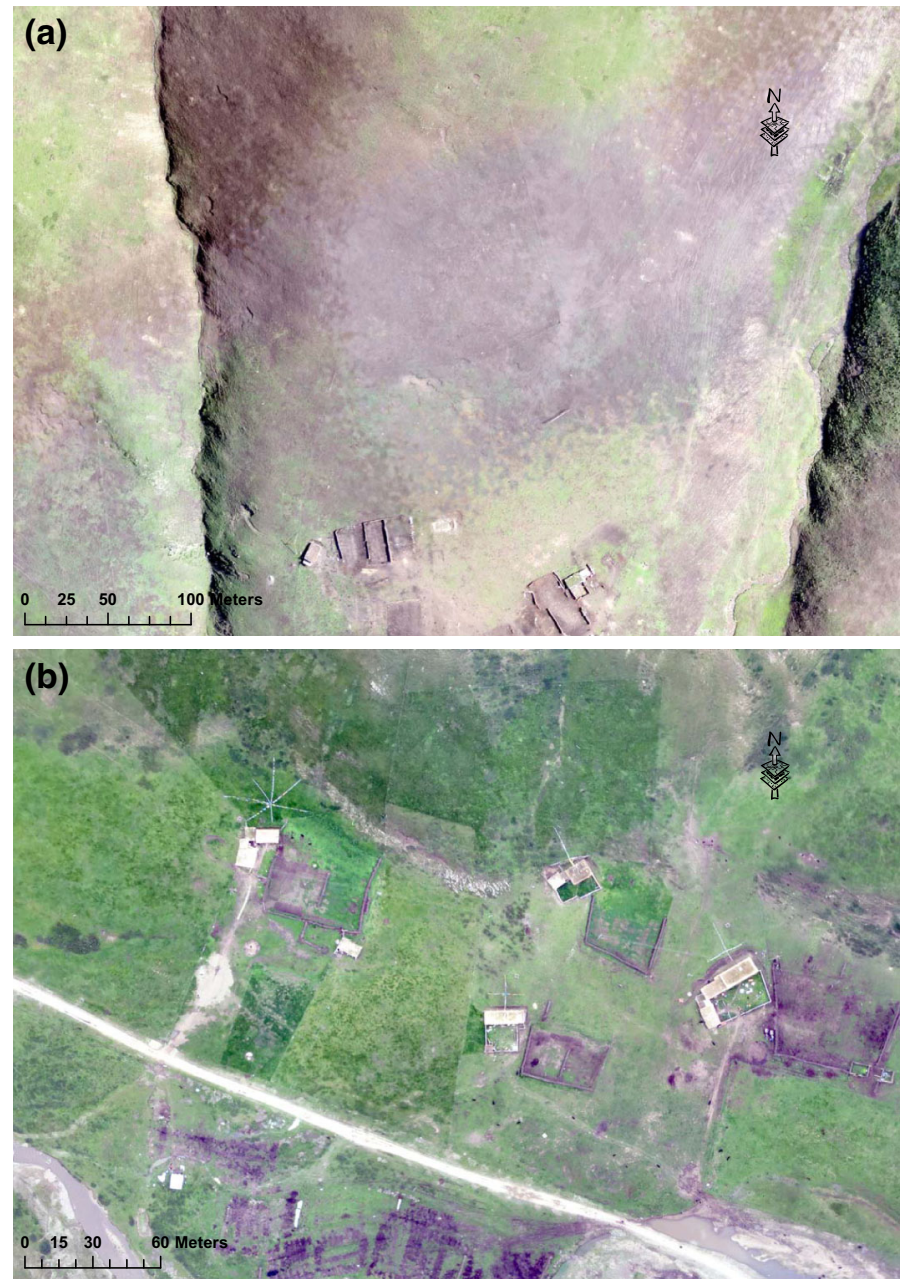

Fig. 4 a Ortho image of a degraded pasture in Nyanpo Yutse on July 2nd, 2014 (Andreas Fritz, unpublished). b Ortho image of a pasture mosaic in Nyanpo Yutse on June 26th, 2014 (Andreas Fritz, unpublished)

Table 1 Measurement of the LUI in Nyanpo Yutse integrating compositional temporal and spatial intensities of pasturing

\begin{tabular}{llll}
\hline & Compositional intensity & Temporal intensity & Spatial intensity \\
\hline Parameter description & $\begin{array}{c}\text { Numbers of yak, } \\
\text { sheep/goats, horses } \\
\text { Lheep unit }\end{array}$ & $\begin{array}{c}\text { Using periods of seasonal } \\
\text { pastures } \\
\text { Days of year }\end{array}$ & Sizes of the pastures \\
\hline
\end{tabular}

The unit for the LUI here is sheep unit per hectare.

One advantage of this LUI definition is that it can be used to compare grazing intensities among various landscape scales and different time periods. It can be calculated on the plot 
level, but also scaled up to the landscape level (Fig. 1). LUI is a quantitative surrogate for the major agricultural disturbance in Nyanpo Yutse, which provides a standardized instrument to examine the correlation between the past land use history and the present local biodiversity distributions and the species turnovers across the landscape. However, when using the LUI to examine the habitat and biodiversity responses we need to carefully distinguish patterns produced by other environmental and ecological factors, e.g. microtopography of habitats, different vegetation compositions on the sunny and shady slopes and the natural succession of alpine plant communities.

\section{Farm level decisions shaping cultural landscapes on Lesvos}

Lesvos is an island located in the north-eastern part of the Aegean, covering an area of $1632.8 \mathrm{~km}^{2}$ and a population of 90,000 inhabitants. Olive cultivations are one of the two major land uses, the other being grazing. Although the number of olive farmers has decreased in the last decades, still today roughly 18,000 farms are declared in the files of the Single Farm Payment of the Common Agricultural Policy (Kizos and Kolovos 2014). The landscape of the olive plantations is a homogenous landscape in the East and Southern parts of the island, terraced to a large extent which is characteristic for the island and part of the local identity (van der Sluis et al. 2014) (Fig. 5). Still, the exact extent of the olive plantations is unknown for two main reasons: first, Lesvos does not have an official land use cadaster, and second the dynamic interplay between clearing, cultivation and abandonment of the plantations makes it difficult to clearly delineate the extent of olive cultivation.

According to the CORINE data [with classes "Olive groves" (223), "Land principally occupied by agriculture, with significant areas of natural value" (243) and "Fruit trees and berry plantations" (222)], olive plantations cover an area of $655.4 \mathrm{~km}^{2}$, i.e. roughly $40 \%$ of the total area of Lesvos (Fig. 6). Most plantations are located from the coastline to an altitude of $200 \mathrm{~m}\left(446.5 \mathrm{~km}^{2}\right.$, or $68.1 \%$ of the total area covered by olive trees), with the

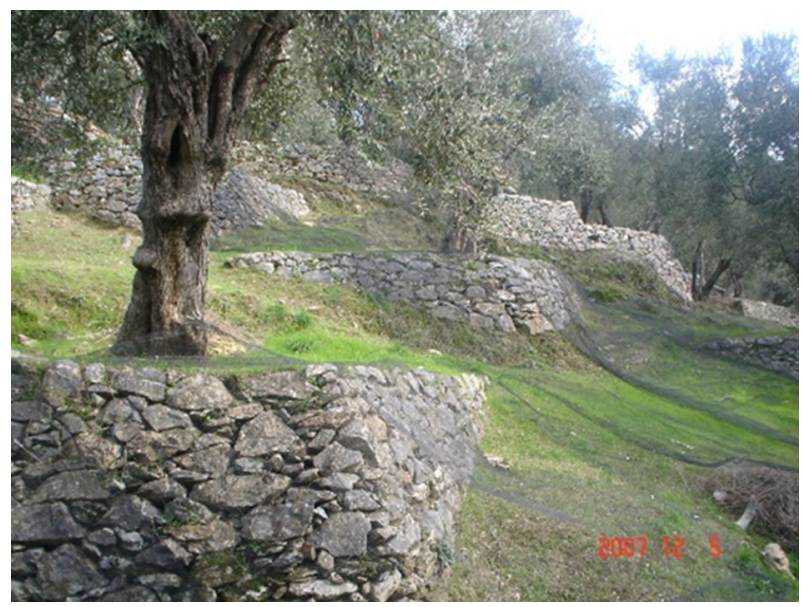

Fig. 5 Olive nets on very well preserved individual limestone terraces in Lesvos, Greece (Photo Thanasis Kizos) 
majority of the rest in 200 to $400 \mathrm{~m}$ altitude $\left(160.4 \mathrm{~km}^{2}\right.$, or $24.4 \%$ of the total olive-tree area) and the remaining $7.2 \%$ located up to $600 \mathrm{~m}$, while only $0.25 \%$ was found above $600 \mathrm{~m}$ on south facing slopes. A considerable part of the olive plantations are located on hilly areas with medium to steep slopes.

Regarding LUI, olive plantations on Lesvos fall into the "traditional" and the "organic" categories, in the typology provided by the OLIVERO project (Stroosnijder et al. 2008the other categories being "semi-intensive" and "intensive irrigated"), described by low labour and material inputs and manual harvesting (Stroosnijder et al. 2008; Duarte et al. 2008; de Graaf et al. 2008). On Lesvos, these two categories are practically one category, as organic cultivation is very similar to "traditional". Olive growing is characterized by low inputs of labour, capital, plant protection products and fertilizers, as olives are harvested manually, with mechanical or manual clearing of the understorey. Only harvesting requires high labour inputs (hired or family labour). This system does not require high levels of mechanization or investments, other than the price of land, which has decreased rapidly during the economic crisis starting in 2008. Pesticides for the clearing of the understorey are applied on a very limited extent and insecticides are only used against the olive fly (Dacus oleae), practiced collectively by special units for all farms with bait spraying, except organic ones which use pheromone traps. The use of fertilizers is also limited or occasional with two major types, commercial soluble fertilizers and olive pomace, again indicating low levels of LUI.

Outputs (annual oil olive production) are generally low, as expected of this system, with biannual full harvests (called maxouli in the local dialect). Data for the twentieth century

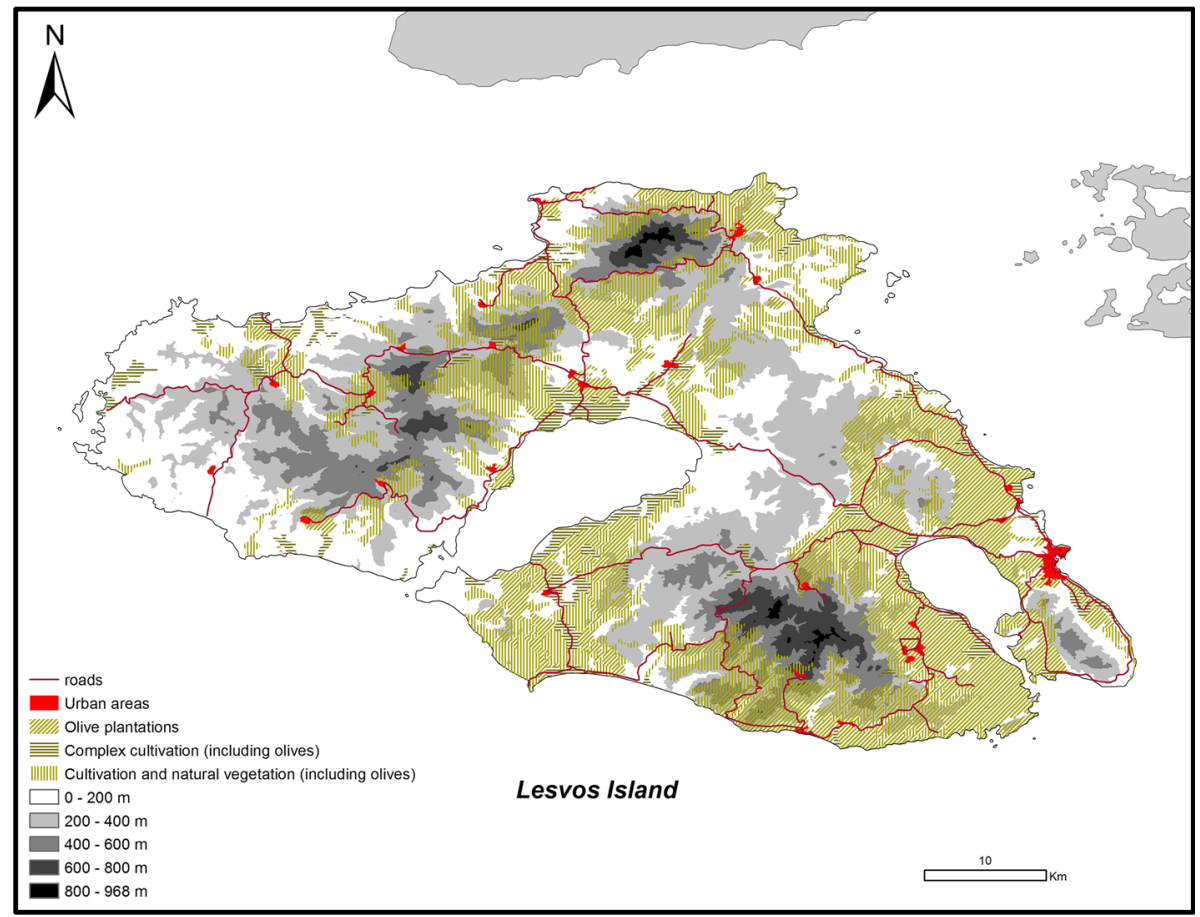

Fig. 6 Extent of olive cultivation on Lesvos 
(Kizos and Koulouri 2005) indicate that the quantities of olive oil have been declining steadily after the 1950s, with a temporary small increase in the 1990s, due to the abundance of cheap hired labour from immigrants from the Balkan countries. The reasons for this steady decrease are economic and demographic_social, as incomes from olive plantations have decreased or remained stable at best for the majority of the farmers. During the last decades, population in many rural areas has decreased by 50 to $60 \%$, while many of the remaining people (especially the younger) sought off-farm employment or livelihoods. The result is that today the extent of land and the number of olive trees under annual cultivation is unknown, but many fields are abandoned, especially in steeper and less accessible areas.

Changes in system properties account for effects of LUI on ecosystem services including biodiversity, nutrient cycling and soil and water quality, and local landscape elements (especially cultivation terraces). Low intensity and especially the infrequent use of pesticides in the understorey makes biodiversity (usually expressed in terms of species richness) high compared to other cultivated areas (Koulouri and Giourga 2007; Kleijn et al. 2009). A recent exploratory study (Karapatsiou 2014) of understorey composition of olive plantations recorded significant differences in the diversity of shrubs according to land management practices and altitude: the lowest diversity was recorded in coastal areas and mechanically cleared or sprayed understorey (average number of species 1.54) and the highest number in non-cleared understoreys regardless of altitude (average number of species 5.4 with a maximum of 14 species). Interestingly, the number of species decreased in abandoned plantations by an average of 4.2 species. These findings are consistent with the analysis of Galinou et al. (2006), who suggest that "olive groves support more birds than their neighboring natural habitats in terms of species richness, abundance and also biodiversity during late winter and these findings are statistically significant. During the breeding period, olive groves continue to support more birds in terms of the above mentioned features" (p. 3). These findings are also consistent with studies in similar areas (Donald et al. 2001; Doxa et al. 2010). The analysis of the diversity and abundance of wild bees revealed that "olive groves on Lesvos Island have the highest value for bees when they are managed rather than abandoned" (Tscheulin et al. (2011), p. 563, see also (Potts et al. 2006)).

Apart from their importance for biodiversity, olive cultivation is also very important symbolically and stands at the core of local identities and culture. Thus, the extensive management of olive plantations on Lesvos provides a number of very important ecological and cultural services. Still, characteristic landscape elements of olive plantations, especially terraces (Fig. 5), are not considered as "valuable" by many farmers and are not properly maintained (Kizos et al. 2010).

This homogenous land use system and landscape of Lesvos can be considered as a "land use legacy" (Plieninger et al. 2011), and the rate of landscape change is low, with various side benefits for biodiversity, high quality products (olive oil)—despite lower productivity-, and a landscape which is attractive for nature-, agri- and rural tourism activities.

On the long term, however, this land use legacy will slowly be lost due to the deterioration of characteristic landscape elements, such as terraces. The question is, how much abandonment and neglect of maintenance will be tolerable, before a point is reached where this legacy will be gone. What will then be the consequences? Will it be possible to reverse unwanted changes and maintain the functions of the system? We propose the landscape level as the right scale between the land use system and biodiversity to address and study these questions, which are at the core of the concept of biocultural diversity. 


\section{Biodiversity consequences of changes in land use intensity in Swiss alpine landscapes}

Alpine landscapes are among the most species rich habitats in Central Europe. They are not only high in biodiversity, but also harbor many threatened species (Fischer et al. 2008). Land use changes, including intensification and abandonment of traditional management, both have negative effects on the present species composition. Pasturing with cattle, sheep and goats and mowing hay meadows to produce winter fodder are the most important agricultural activities in these landscapes (Fig. 7). In Switzerland alone, $11 \%$ of the total area of the country, i.e. $4650 \mathrm{~km}^{2}$ are explicitly used as summer pastures, foremost located in altitudes of 1000-2500 m (Herzog et al. 2013). The intensity of pasturing depends on various factors, such as the type of animals, as they differ in browsing as well as in how they use the pasture spatially. Thus, it is possible to express LUI in alpine landscapes in parameters similar to the ones in the Nyanpo Yutse land use systems, by distinguishing compositional intensity, temporal intensity and spatial intensity of the main land uses, i.e. pasturing and mowing (Table 2). However, LUI determined on e.g. the farm level, is not uniformly affecting the land, i.e. the plot or even the $\mathrm{m}^{2}$ level (Fig. 1). GPS-tracking devices, recording the animal activity (walking, grazing, resting) allow to assess pasturing intensity and to be able to study correlations of this intensity to factors, such as slope, distance to the farm building and vegetation type (e.g. Homburger et al. 2012) and to establish links to biodiversity, e.g. species occurrence.

Several studies investigated changes in species composition of hay meadows, by repeating historic vegetation relevés. Comparing the variability of species composition of Golden Oat meadows within and between two study areas from the 1940s to 2008, Homburger and Hofer (2012) found a decrease in species richness at the plot level (alpha diversity), but an increase in variability of species composition within the study area (beta diversity), and also of the total number of species in all relevés (gamma diversity) mostly due to an increase in generalist species, which overruled the loss of Red List species. On a regional level, the study revealed a loss of floristic differentiation between the two study areas. The authors interpret these developments as a result of agricultural intensification,

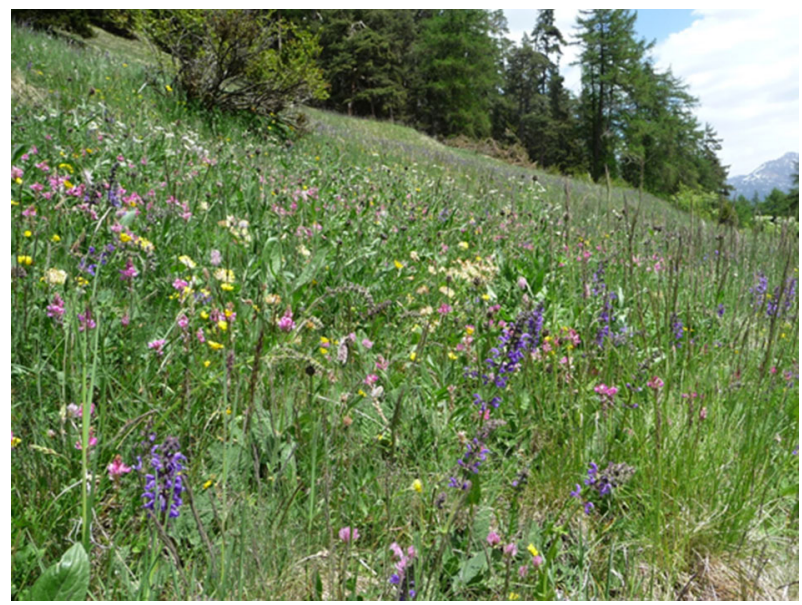

Fig. 7 Species-rich meadow close to Vna, in the Lower Engadine, Switzerland (Photo Matthias Bürgi) 
Table 2 Measurement of the LUI in Swiss alpine landscapes integrating compositional temporal and spatial intensities of pasturing $(\mathrm{P})$ and mowing $(\mathrm{M})$

\begin{tabular}{llll}
\hline & Compositional intensity & Temporal intensity & Spatial intensity \\
\hline $\begin{array}{c}\text { Parameter } \\
\text { description }\end{array}$ & $\begin{array}{c}\text { P: numbers of cattle, } \\
\text { sheep, goats }\end{array}$ & $\begin{array}{l}\text { P: using periods of seasonal pastures } \\
\text { M: specific practice }\end{array}$ & $\begin{array}{l}\text { P: temporal regime } \\
\text { M: size of the pastures }\end{array}$ \\
$\begin{array}{l}\text { Land Use } \\
\text { Intensity }\end{array}$ & $\begin{array}{l}\text { M: cattle unit } \\
\text { irrigation, } \\
\text { fertilization }\end{array}$ & $\begin{array}{l}\text { P: days of year } \\
\text { M: frequency, timing, amount of } \\
\text { irrigation and fertilization }\end{array}$ & $\begin{array}{c}\text { P: areas in ha } \\
\text { irrigated, fertilized }\end{array}$ \\
& & &
\end{tabular}

specifically the type and quantity of fertilization and the date and frequency of cutting (see also Fischer et al. 2008). The unexpected increase of beta diversity, is interpreted as a consequence of more individualistic management and a diversification of farming styles. This result brings up an interesting question: Is an increase of diversity of farming styles also an increase in cultural diversity of farming practices, even if the new practices are not rooted in local or regional traditions?

The cultural footprint on land use diversity and subsequent plant species richness in alpine grasslands has explicitly been studied by Maurer et al. (2006). They compared the effect of Romanic, Germanic and Walser traditions at the landscape and the parcel level and conclude that a high diversity of land use types is important to maintain the high diversity of plant species.

Traditional management was shaped by various cultural context (such as the German, Romanic and Walser tradition in the Swiss alps), fostering specific land use systems on the landscape level, and stabilizing these pattern over centuries. Today, the farmers' decisions are less shaped by such regional factors, but larger-scale driving forces, such as agricultural policies, leading to more individualistic decisions and farm-level diversification. The general trend to land use intensification on the plots which are still farmed, however, is ubiquitous, often driven by the economic need to reach higher productivity by reducing workload per area with technological innovations (Maurer et al. 2006)—a trend which can be fostered or slowed down by agricultural subsidies. So-called ameliorations projects were conducted in most municipalities throughout Switzerland, to increase farming efficiency, which most often goes hand in hand with an increase in farming intensity. These projects involve reparcelling of the land to gain larger management units, the construction of new roads for improved access to the land, and drainage and irrigation for optimal growing conditions (Graf et al. 2014a; Bürgi et al. 2015). In a recent study, Graf et al. (2014b) looked at the effects of modern irrigation, often justified to minimize drought stress in dry years, on species composition of alpine meadows. The authors document a decrease in species rich extensively managed meadows as a consequence of newly erected sprinkler installations. Not only floristic, but also faunal changes can be linked to increasing farming intensity in the Swiss alps. For example meadow breeding birds are especially vulnerable to changes in mowing dates, shifts from haymaking to silage, and irrigation (Müller et al. 2005).

These examples underline the core role of farmers as main agents in shaping agricultural landscapes and illustrate the importance of insights into the factors influencing farmlevel decisions, i.e. the driving forces in Fig. 1. Schmitzberger et al. (2005) suggest to integrate the concept of farming styles and they distinguish for Austria eight different 
farming styles, i.e. yield optimizer, traditionalist, innovative, support optimizer, idealist, part-time farmer, forced farmer and social farmer. The authors suggest to use this classification to target conservation efforts and develop subsidy schemes more efficiently and effectively. These findings most likely can also be transferred to the situation in Swiss alpine landscapes, as both neighboring countries face similar environmental constraints and grasslands are also among the most species rich habitats in Austria (Zulka et al. 2014). The short review on studies looking at the effect of LUI on biodiversity and the degree cultural aspects are reflected therein suggests that special attention should be paid to analyzing the local land use tradition and the related LUI beforehand, as they were determining the biodiversity present. Present land management, performed by whatever farm type distinguished above, will have to be compared regarding the related LUI to the local tradition. It might well be that land managed by part-time farmers, who typically experience less economic pressure in their farming activity than full-time farmers, is used with a LUI more similar to the one of the traditional land management, compared to e.g. traditionalists, that run a full-time farm and have to develop long-term perspectives for their operation under the present driving forces (Fig. 1). Questions similar to the ones asked for Lesvos arise, especially as the traditional land management in Swiss alpine landscapes also provides high services for recreation and tourism: How much changes in LUI are tolerable without putting the biodiversity and other services linked to traditional management at risk?

\section{Conclusions}

Insights into how land use affects biodiversity is to be gained on levels where causal relationships can be studied, i.e. where the actors, such as farmers act in agricultural landscapes and species react. Minor changes in LUI can have major changes on biodiversity, such as in the example of Lesvos, where olive plantations still dominate large parts of the island, but a slow decline in cultivation leads to changes in biodiversity. The changes in LUI can be assessed on the level of overall input and output analyses as well as on the farm level, on which additionally specific decisions regarding land management and the causal driving forces can be studied.

Most changes in LUI do not have consequences for land cover and will therefore not be visible on land cover maps. Even most land use maps are not be specific enough to distinguish between various levels of intensity within the same land use category (but see van Asselen and Verburg 2013), and therefore changes in LUI, such as irrigation, drainage, changes in grazing intensity or mowing dates, as described in the Swiss example, have to be assessed and mapped based on a different approach. The Chinese example illustrates how this could be done, as the LUI index proposed for grassland management, could easily be mapped. Yet, causal relations of such an index of LUI to biodiversity are not to be expected, as natural driving forces have an impact on biodiversity as well and have to be considered as such and in their interaction with driving forces shaped by culture.

The case studies presented have shown that now only culture is hard to grasp, but so is biodiversity: Which biodiversity are we talking about? Which spatial resolution-again, from plot to the landscape level—is considered to be most relevant? Homburger and Hofer (2012) show for Swiss alpine grasslands how a decline in alpha diversity (plot level), can be paralleled by an increase in beta (variability of species composition within the study area) and gamma diversity (total number of species in all relevés), and a loss of floristic 
differentiation between two study areas. On one hand, it is important to define the scale, but also the aim: Do we simple care about total species number or does it matter if the changes determined are caused by generalist species, or Red List species?

Interesting links to the cultural dimension of LUI appear, if we realize how the loss of local land use traditions might on one hand lead to more similar land management pattern between regions. At the same time, they might also open up new ways of farming-leading to an increase in farming styles within the same community, i.e. contributing to an increase in beta diversity of land management. Land use and LUI can be heavily shaped by historical developments and political driving forces, as in the Chinese example, which can lead to differentiation as well as to homogenization on various scales.

Land use changes, their consequences and the driving forces behind these changes have to be studied in detail on scales from the plot to the landscape-not the least as a base to inform the public about ongoing processes and the related consequences, e.g. for the future of olive cultivation and the related cultural landscape in Lesvos. Conceptualizing and operationalizing LUI is therefore of vital importance, and various approaches are already available, depending on the specific system under study and the aims. We consider Fig. 1 as a contribution towards a good framework for exploring the multi-scale links between land use and biodiversity and to learn more about the interconnectedness of humans and their environment and the resulting consequences for society, landscape, and biodiversity.

Acknowledgments Part of the research leading to these results have received funding from the European Union's Seventh Framework Programme under grant agreement number 603447, HERCULES, with the RTD activities of the Environmental Thematic Priority. The Rufford Foundation generously supported the 2014 field work of the land use history and avian biodiversity research in Nyanpo Yutse. We thank the two reviewers for their comments.

\section{References}

Abramov O, Mehler A (2011) Automatic language classification by means of syntactic dependency networks. J Quant Linguist 18:291-336

Antrop M (2004) Landscape change and the urbanization process in Europe. Landscape and Urban Planning 67:9-26

Antrop M (2006) From holistic landscape synthesis to transdisciplinary landscape management. In: Tress B, Tress G, Fry G, Opdam P (eds) From landscape research to landscape planning: aspects of integration, education and application, vol 12., Wageningen UR Frontis SeriesSpringer, Dordrecht, pp 27-50

Arthur AD, Pech RP, Davey C, Jiebu Yanming Z, Hui L (2008) Livestock grazing, plateau pikas and the conservation of avian biodiversity on the Tibetan Plateau. Biol Conserv 141:1972-1981. doi:10.1016/j. biocon.2008.05.010

Blüthgen N, Dormann CF, Prati D, Klaus VH, Kleinebecker T, Hölzel N, Alt F, Boch S, Gockel S, Hemp A, Müller J, Nieschulze J, Renner SC, Schöning I, Schumacher U, Socher SA, Wells K, Birkhofer K, Buscot F, Oelmann Y, Rothenwöhrer C, Scherber C, Tscharntke T, Weiner CN, Fischer M, Kalko EKV, Linsenmair KE, Schulze ED, Weisser WW (2012) A quantitative index of land-use intensity in grasslands: integrating mowing, grazing and fertilization. Basic Appl Ecol 13:207-220

Börschig C, Klein AM, von Wehrden H, Krauss J (2013) Traits of butterfly communities change from specialist to generalist characteristics with increasing land-use intensity. Basic Appl Ecol 14:547-554

Bürgi M, Hersperger A, Schneeberger N (2004) Driving forces of landscape change - current and new directions. Landsc Ecol 19:857-868

Bürgi M, Salzmann D, Gimmi U (2015) 264 years of change and persistency in an agrarian landscape. A case study from the Swiss lowlands. Landsc Ecol

Carolan M (2012) The sociology of food and agriculture. Earthscan, London

de Graaf J, Duran Zuaro VH, Jones N, Fleskens L (2008) Olive production systems on sloping land: prospects and scenarios. J Environ Manag 89:129-139 
Deguines N, Jono C, Baude M, Henry M, Julliard R, Fontaine C (2014) Large-scale trade-off between agricultural intensification and crop pollination services. Front Ecol Environ 12:212-217

Diacon-Bolli JC, Dalang T, Holderegger R, Bürgi M (2012) Heterogeneity fosters biodiversity - linking history and ecology in dry calcareous grasslands. Basic Appl Ecol 13:641-653

Donald PF, Green RE, Heath MF (2001) Agricultural intensification and the collapse of Europe's farmland bird populations. Proc R Soc B. 268:25-29

Doxa A, Bas Y, Paracchini ML, Pointereau P, Terres JM, Jiguet F (2010) Low-intensity agriculture increases farmland bird abundances in France. J Appl Ecol 47:1348-1356

Duarte F, Jones N, Fleskens L (2008) Traditional olive orchards on sloping land: sustainability or abandonment? J Environ Manag 89:86-98

Erb KH, Haberl H, Rudbeck Jepsen M, Kuemmerle T, Lindner M, Müller D, Verburg PH, Reenberg A (2013) A conceptual framework for analysing and measuring land-use intensity. Current opinion in environmental sustainability 5:464-470

Erb KH, Niedertscheider M, Dietrich JP, Schmitz C, Verburg PH, Rudbeck Jepsen M, Haberl H (2014) Conceptual and empirical approaches to mapping and quantifying land-use intensity. In: FischerKowalski M, Reenberg A, Schaffartzik A, Mayer A (eds) Human-environment interactions, vol 4. Springer, New York

Farina A (2006) Principles and methods in landscape ecology: Towards a science of landscape. Springer, Berlin

Fischer M, Rudmann-Maurer K, Weyand A, Stöcklin J (2008) Agricultural land use and biodiversity in the Alps. Mt Res Dev 28:148-155

Folke C, Carpenter SR, Walker B, Scheffer M, Chapin T, Rockström J (2010) Resilience thinking: integrating resilience, adaptability and transformability, Ecol Soc 15(4)

Galinou E, Grammatikaki M, Dimitrakopoulos, P. and Margaris, N. (2006) An evaluation for the importance of olive groves for birds, paper presented in the 10th international congress on the zoogeography and ecology of Greece and adjacent regions, Patras, Greece, available at https://www.researchgate.net/ publication/267746412_An_evaluation_for_the_importance_of_olive_groves_for_birds. Accessed 21 March 2015

Galluzzi G, Eyzaguirre P, Negri V (2010) Home gardens: neglected hotspots of agro-biodiversity and cultural diversity. Biodivers Conserv 19:3635-3654

Gaudino S, Goia I, Borreani G, Tabacco E, Sacco D (2014) Cropping system intensification grading using an agro-environmental indicator set in northern Italy. Ecol Ind 40:76-89

Gimmi U, Bürgi M, Stuber M (2008) Reconstructing anthropogenic disturbance regimes in forest ecosystems-a case study from the Swiss Rhone valley. Ecosystems 11:113-124

Golok Overview Editors' Group (ed) (2009) Overview of Golok Tibetan Autonomous Prefecture, revised version. Overview of minority autonomous regions in China. Nationality Publisher, Beijing

Graf R, Korner P, Birrer S (2014a) Bewässerungsanlagen als Ursache für die Nutzungsintensivierung von Grünland im Engadin. Agrarforschung Schweiz 5:406-413

Graf R, Müller M, Korner P, Jenny M, Jenni L (2014b) 20\% loss of unimproved farmland in 22 years in the Engadin, Swiss Alps. Agric Ecosyst Environ 185:48-58

Haberl H, Erb KH, Krausmann F, Gaube V, Bondeau A, Plutzar C, Gingrich S, Lucht W, Fischer-Kowalski M (2007) Quantifying and mapping the human appropriation of net primary production in earth's terrestrial ecosystems. Proc Natl Acad Sci USA 104:12942-12947

Harris RB (2010) Rangeland degradation on the Qinghai-Tibetan plateau: a review of the evidence of its magnitude and causes. J Arid Environ 74:1-12. doi:10.1016/j.jaridenv.2009.06.014

Herzog F, Oehen B, Raaflaub M, Szerencsits E (2013) Warum es die Alpwirtschaft nicht gibt: Versuch einer Beschreibung. In: Lauber S, Herzog F, Seidl I, Böni R, Bürgi M, Gmür P, Hofer G, Mann S, Raaflaub M, Schick M, Schneider M, Wunderli R (eds.) (2013) Zukunft der Schweizer Alpwirtschaft: Fakten, Analysen und Denkanstösse aus dem Forschungsprogramm AlpFUTUR. Birmensdorf, Eidg. Forschungsanstalt für Wald, Schnee und Landschaft WSL; Zürich-Reckenholz, Forschungsanstalt Agroscope, pp 19-35

Homburger H, Hofer G (2012) Diversity change of mountain hay meadows in the Swiss Alps. Basic Appl Ecol 13:132-138

Homburger H, Schneider MK, Hilfiker S, Scherer-Lorenzen M, Lüscher A (2012) Measuring grazing intensity in heterogeneous pastures using GPS-tracking. Grassl Sci Eur 17:213-215

Howard PJ (2011) An introduction to landscape. Ashgate, Farnham

Humphrey C, Sneath D (1999) The End of Nomadism? Society, State, and the Environment in Inner Asia. Duke University Press, Durham

Jiuzhi County Annals Editor's Group (ed) (2005) Jiuzhi County Annals. Sanqin Publisher, Xi'an 
Jiuzhi County Government Office (2012) Implementation plan of grassland ecological conservation compensation mechanism of Jiuzhi County in 2011. Jiuzhi

Karapatsiou E (2014) Biodiversity of olive plantations on Lesvos: evidence from the Gera area, unpublished masters' thesis in the Postgraduate programme "Environmental Policy and Management", Department of Environmental Studies. University of the Aegean, Mytilini

Kizos T, Kolovos C (2014) Anaparagontas palaioteres adikies h pros megaliteri dikaosini? H horiki diastasi tis Politikis Eniaias Enishisis stin Ellada [Reproducing older injustices or towards more justice? The spatial aspect of the Single Farm Payment Policy in Greece], paper presented in ETAGRO, Athens, 21-22 Nov 2014 (in Greek)

Kizos T, Koulouri M (2005) Economy, demographic changes and morphological transformation of the agricultural landscape of Lesvos, Greece. Hum Ecol Rev 21(2):183-192

Kizos T, Dalaka A, Petanidou T (2010) Farmers' attitudes and landscape change: evidence from the abandonment of terraced cultivations on Lesvos, Greece. Agric Hum Values 27:199-212

Kleijn D, Kohler F, Báldi A, Batáry P, Concepcion ED, Clough Y, Diaz M, Gabriel D, Holzschuh A, Knop E, Kovács A, Marshall EJP, Tscharntke T, Verhulst J (2009) On the relationship between farmland biodiversity and land-use intensity in Europe. Proc R Soc B 276:903-909

Koulouri M, Giourga C (2007) Land abandonment and slope gradient as key factors of soil erosion in Mediterranean terraced lands. Catena 69:274-281

Kuemmerle T, Erb KH, Meyfroidt P, Müller D, Verburg PH, Estel S, Haberl H, Hostert H, Rudbeck Jepsen M, Kastner T, Levers C, Lindner M, Plutzar C, Verkerk PJ, van der Zanden E, Reenberg A (2013) Challenges and opportunities in mapping land use intensity globally. Curr Opin Environ Sustain 5:484-493

Loh J, Harmon D (2005) A global index of biocultural diversity. Ecol Ind 5:231-241

Lomba A, Guerra C, Alonso J, Honrado JP, Jongman R, McCracken D (2014) Mapping and monitoring high nature value farmlands: challenges in European landscapes. J Environ Manage 143:140-150

Maffi L (2005) Linguistic, cultural and biological diversity. Annu Rev Anthropol 34:599-617

Magurran AE (2004) Measuring biological diversity. Blackwell Publishing, Oxford

Marcucci DJ (2000) Landscape history as a planning tool. Landsc Urban Plan 49:7-81

Maurer K, Weyand A, Fischer M, Stöcklin J (2006) Old cultural traditions, in addition to land use and topography, are shaping plant diversity of grasslands in the Alps. Biol Conserv 130:438-446

Miehe G, Miehe S, Kaiser K, Reudenbach C, Behrendes L, Duo L, Schluetz F (2009) How old is pastoralism in Tibet? An ecological approach to the making of a Tibetan landscape. Palaeogeogr Palaeoclimatol Palaeoecol 276:130-147

Müller M, Spaar R, Schifferli L, Jenni L (2005) Effects of changes in farming of subalpine meadows on a grassland bird, the whinchat (Saxicola rubetra). J Ornithol 146:14-23

Nagendra H, Reyers B, Lavorel S (2013) Impacts of land change on biodiversity: making the link to ecosystem services. Curr Opin Environ Sustain 5:503-508

Plieninger T, Schaich H, Kizos T (2011) Land-use legacies in the forest structure of silvopastoral oak woodlands in the Eastern Mediterranean. Reg Environ Change 11:603-615

Potts SG, Petanidou T, Roberts S, O’Toole C, Hulbert A, Willmer P (2006) Plant-pollinator biodiversity and pollination services in a complex Mediterranean landscape. Biol Conserv 129:519-529

Russell EWB (1993) Discovery of the subtle. In: McDonnell MJ, Pickett STA (eds) Humans as components of ecosystems. Springer, New York

Schmitzberger I, Wrbka T, Steurer B, Aschenbrenner G, Peterseil J, Zechmeister HG (2005) How farming styles influence biodiversity maintenance in Austrian agricultural landscapes. Agric Ecosyst Environ 108:274-290

Stroosnijder L, Mansinho MI, Palese AM (2008) OLIVERO: the project analysing the future of olive production systems on sloping land in the Mediterranean basin. J Environ Manag 89:75-85

Sutherland WJ (2003) Parallel extinction risk and global distribution of languages and species. Nature 423:276-279

Sutton M, Anderson E (2004) Introduction to cultural ecology. AltaMira Press, USA

Targetti S, Herzog F, Geijzendorffer IR, Wolfrum S, Arndorfer M, Balàzs K, Choisis JP, Dennis P, Eiter S, Fjellstad W, Friedel JK, Jeanneret P, Jongman RHG, Kainz M, Luescher G, Moreno G, Zanetti T, Sarthou JP, Stoyanova S, Wiley D, Paoletti MG, Viaggi D (2014) Estimating the cost of different strategies for measuring farmland biodiversity: evidence from a Europe-wide field evaluation. Ecol Ind 45:434-443

Tscheulin T, Neokosmidis L, Petanidou T, Settele J (2011) Influence of landscape context on the abundance and diversity of bees in Mediterranean olive groves. Bull Entomol Res 101:557-564. doi:10.1017/ S0007485311000149 
Tsilimigkas G, Kizos T (2014) Space, pressures and the management of the Greek landscape. Geografiska Annaler 96:159-175

Turner BL, Lambin EF, Reenberg A (2007) The emergence of land change science for global environmental change and sustainability. Proc Natl Acad Sci 104:20666-20671

van Asselen S, Verburg PH (2013) Land cover change or land-use intensification: simulating land system change with a global-scale land change model. Glob Change Biol 19:3648-3667

van der Sluis T, Kizos T, Pedroli B (2014) Landscape change in Mediterranean farmlands: impacts of land abandonment on cultivation terraces in Portofino (Italy) and Lesvos (Greece). J Landsc Ecol 7:23-44

Zhang L, Liu J, McShea WJ, Wu Y, Wang D, Lü Z (2014) The impact of fencing on the distribution of Przewalski's gazelle. J Wildl Manag 78:255-263. doi:10.1002/jwmg.653

Zhou HK, Tang YH, Zhao XQ, Zhou L (2006) Long-term grazing alters species composition and biomass of a shrub meadow on the Qinghai-Tibet Plateau. Pak J Bot 38:1055-1069

Zulka KP, Abensperg-Traun M, Milasowszky N, Bieringer G, Gereben-Krenn BA, Holzinger W, Holzler G, Rabitsch W, Reischutz A, Querner P, Sauberer N, Schmitzberger I, Willner W, Wrbka T, Zechmeister H (2014) Species richness in dry grassland patches of eastern Austria: a multi-taxon study on the role of local, landscape and habitat quality variables. Agric Ecosyst Environ 182:25-36 